\title{
Gender Difference in Baroreflex Sensitivity to Predict Cardiac and Cerebrovascular Events in Type 2 Diabetic Patients
}

\author{
Kunio Yufu, MD, PhD; Naohiko Takahashi, MD, PhD; Norihiro Okada, MD; \\ Osamu Wakisaka, MD, PhD; Tetsuji Shinohara, MD, PhD; Mikiko Nakagawa, MD, PhD; \\ Masahide Hara, MD, PhD; Hironobu Yoshimatsu, MD, PhD; Tetsunori Saikawa, MD, PhD
}

\begin{abstract}
Background: Cardiovascular autonomic neuropathy is a major complication in patients with diabetes mellitus (DM), and baroreflex sensitivity (BRS) reportedly can predict cardiovascular prognosis in type 2 DM patients. The hypothesis that cardiovascular events are associated with gender differences in BRS was tested in the present study.
\end{abstract}

\begin{abstract}
Methods and Results: From 1998, we have evaluated BRS by phenylephrine methods in 185 consecutive type 2 DM patients. The long-term prognostic value of BRS was compared between 91 female (58 \pm 12 years) and 94 male patients ( $58 \pm 11$ years). There was no significant difference in age or severity and duration of DM between the 2 groups. When compared to male, the BRS value in female patients was significantly lower $(9.26 \pm 6.0$ vs. $5.97 \pm 5.0 \mathrm{~ms} / \mathrm{mmHg}, \mathrm{P}<0.0001)$. During a mean of 62.7 months of follow-up, 16 female patients developed cardiovascular events (17.6\%) including stroke, acute myocardial infarction, angina pectoris requiring percutaneous coronary intervention or coronary artery bypass grafting and congestive heart failure requiring admission, while only 4 male patients developed events $(4.3 \%, \mathrm{P}<0.005)$. In females, the Kaplan-Meier curves revealed that those with depressed BRS $(<6 \mathrm{~ms} / \mathrm{mmHg}$ ) had a higher incidence of cardiovascular events than those with preserved BRS $(\mathrm{P}<0.05)$, but this relationship was not observed in male patients.
\end{abstract}

Conclusions: Although the reason why females had a more depressed BRS remains unclear, our findings demonstrated that a depressed BRS value can accurately predict cardiovascular events, especially in female patients with type 2 DM. (Circ J 2011; 75: 1418-1423)

Key Words: Autonomic nervous system; Cardiovascular diseases; Diabetes mellitus; Gender

A utonomic imbalance, characterized by increased sympathetic activity and/or decreased parasympathetic activity, is tightly related to cardiovascular mortality. Among several autonomic markers, baroreflex sensitivity (BRS) has predicted cardiac mortality in patients with previous myocardial infarction (MI). ${ }^{1-5}$ The ATRAMI study demonstrated that, independent from left ventricular ejection fraction, depressed BRS was an independent predictor for cardiac mortality, ${ }^{1}$ and impaired BRS has been also associated with increased long-term mortality after acute ischemic stroke. ${ }^{6}$ In our series of clinical studies investigating BRS using the phenylephrine method in patients with type 2 diabetes mellitus (DM) without structural heart disease, ${ }^{7-11}$ the presence of essential hypertension, ${ }^{7}$ microalbuminuria, ${ }^{8}$ high levels of high-sensitivity C-reactive protein ${ }^{9}$ or brain natriuretic peptide, ${ }^{10}$ or hypoadiponectinemia ${ }^{11}$ have been associated with low levels of BRS. Abdel-Rahman et al first reported in healthy young subjects that females had less sensi- tive baroreflex control of heart rate than males, ${ }^{12}$ and several studies have reported on gender-related differences regarding the baroreflex response. ${ }^{12-17}$ However, it remains unclear whether there is a gender difference in BRS as a predictive value, so the hypothesis that cardiovascular events are associated with gender differences in BRS was tested in Japanese type $2 \mathrm{DM}$ patients without structural heart disease.

\section{Editorial p 1320}

\section{Patient Selection}

\section{Methods}

A total of 210 patients with type 2 DM who were admitted to Oita University Hospital from 1998 to 2004 for blood glucose control were recruited. Type $2 \mathrm{DM}$ was defined as a fasting plasma glucose concentration $\geq 126 \mathrm{mg} / \mathrm{dl}$, a 2 -h

Received November 9, 2010; revised manuscript received January 6, 2011; accepted February 1, 2011; released online April 9, 2011 Time for primary review: 15 days

Department of Internal Medicine 1 (N.O., O.W., T. Shinohara, M.H., H.Y.), Department of Laboratory Examination and Diagnostics (K.Y., N.T., M.N., T. Saikawa), Faculty of Medicine, Oita University, Yufu, Japan

Mailing address: Kunio Yufu, MD, PhD, Department of Laboratory Examination and Diagnostics, Faculty of Medicine, Oita University,

1-1 Idaigaoka, Hasama, Yufu 879-5593, Japan. E-mail: yufukuni@ oita-u.ac.jp

ISSN-1346-9843 doi:10.1253/circj.CJ-10-1122

All rights are reserved to the Japanese Circulation Society. For permissions, please e-mail: cj@j-circ.or.jp 


\begin{tabular}{|c|c|c|c|c|c|}
\hline & \multicolumn{2}{|c|}{ Male } & \multicolumn{2}{|c|}{ Female } & \multirow[b]{2}{*}{$P$ value } \\
\hline & $\begin{array}{c}\text { BRS } \geq 6.0 \\
(n=63)\end{array}$ & $\begin{array}{c}\text { BRS }<6.0 \\
(n=31)\end{array}$ & $\begin{array}{c}\text { BRS } \geq 6.0 \\
(n=36)\end{array}$ & $\begin{array}{c}\text { BRS }<6.0 \\
(n=55)\end{array}$ & \\
\hline Age (years) & $56 \pm 11$ & $60 \pm 11$ & $54 \pm 13$ & $61 \pm 11^{\dagger}$ & $<0.05$ \\
\hline Diabetes duration (years) & $11 \pm 9^{\dagger}$ & $10 \pm 9$ & $6 \pm 5$ & $11 \pm 7^{\dagger}$ & $<0.05$ \\
\hline \multicolumn{6}{|l|}{ Drug use $(\%)$} \\
\hline ARB & 19.1 & 19.4 & 13.9 & 10.9 & NS \\
\hline ACEI & 19.1 & 9.7 & 5.6 & 10.9 & NS \\
\hline CCB & 33.3 & 29.0 & 25.0 & 41.8 & NS \\
\hline Statin & 27.0 & 29.0 & 36.1 & 41.8 & NS \\
\hline Hypertension (\%) & 49 & 65 & 44 & 65 & NS \\
\hline Dyslipidemia (\%) & 71 & 81 & 72 & 71 & NS \\
\hline $\mathrm{BMI}\left(\mathrm{kg} / \mathrm{m}^{2}\right)$ & $25 \pm 5$ & $26 \pm 7$ & $26 \pm 5$ & $26 \pm 5$ & NS \\
\hline Heart rate (beats/min) & $68 \pm 8$ & $73 \pm 8$ & $69 \pm 8$ & $69 \pm 9$ & NS \\
\hline $\mathrm{SBP}(\mathrm{mmHg})$ & $122 \pm 19$ & $131 \pm 20$ & $121 \pm 17$ & $135 \pm 20^{*, \dagger}$ & $<0.0005$ \\
\hline $\mathrm{DBP}(\mathrm{mmHg})$ & $66 \pm 12$ & $74 \pm 12$ & $67 \pm 15$ & $69 \pm 11$ & NS \\
\hline FPG (mg/dl) & $142 \pm 43$ & $157 \pm 48$ & $156 \pm 50$ & $161 \pm 57$ & NS \\
\hline $\mathrm{HbA}_{1 \mathrm{c}}(\%)$ & $7.8 \pm 1.6$ & $8.0 \pm 1.7$ & $8.6 \pm 2.1$ & $8.4 \pm 1.6$ & NS \\
\hline Total cholesterol (mg/dl) & $188 \pm 32$ & $194 \pm 49$ & $204 \pm 41$ & $206 \pm 47$ & NS \\
\hline Triglyceride (mg/dl) & $130 \pm 85$ & $156 \pm 111$ & $132 \pm 50$ & $146 \pm 182$ & NS \\
\hline LDL-C (mg/dl) & $114 \pm 27$ & $119 \pm 33$ & $130 \pm 39$ & $123 \pm 40$ & NS \\
\hline HDL-C (mg/dl) & $46 \pm 13$ & $39 \pm 10^{\dagger, \neq}$ & $49 \pm 13$ & $50 \pm 14$ & $<0.005$ \\
\hline Uric acid (mg/dl) & $5.6 \pm 1.4^{\ddagger}$ & $5.8 \pm 1.6^{\ddagger}$ & $5.0 \pm 1.5$ & $4.9 \pm 1.2$ & $<0.01$ \\
\hline eGFR $\left(\mathrm{ml} \cdot \mathrm{min} \cdot 1.73 \mathrm{~m}^{-2}\right)$ & $76 \pm 24$ & $70 \pm 25^{\dagger}$ & $90 \pm 30$ & $79 \pm 33$ & $<0.05$ \\
\hline $\mathrm{BRS}(\mathrm{ms} / \mathrm{mmHg})$ & $12.0 \pm 5.3$ & $3.5 \pm 2.0^{\star}, \dagger$ & $10.7 \pm 4.7$ & $2.8 \pm 2.0^{*, \dagger}$ & $<0.0001$ \\
\hline
\end{tabular}

Data are mean \pm SD.

${ }^{*}$ vs. male (BRS $\geq 6.0$ ), ${ }^{\dagger}$ vs. female (BRS $\geq 6.0$ ), ${ }^{\star}$ vs. female (BRS $<6.0$ ).

BRS, baroreflex sensitivity; ARB, angiotensin II receptor blocker; ACEI, angiotensin converting enzyme inhibitor; $C C B$, calcium channel blocker; BMI, body mass index; SBP, systolic blood pressure; DBP, diastolic blood pressure; FPG, fasting plasma glucose; Hb, hemoglobin; LDL-C, low-density lipoprotein cholesterol; HDL-C, high-density lipoprotein cholesterol; eGFR, estimated glomerular filtration rate.

plasma glucose concentration following a $75 \mathrm{~g}$ oral glucose load $\geq 200 \mathrm{mg} / \mathrm{dl}$, or the self-reported use of antidiabetic medication. ${ }^{18}$ None of the patients had organic heart disease as determined by physical examination, chest X-ray, 12-lead ECG, echocardiography, and ${ }^{201}$ thallium cardiac scintigraphy. Myocardial ischemia was excluded by treadmill exercise ECG testing. Essential hypertension was defined as diastolic blood pressure (BP) $\geq 90 \mathrm{mmHg}$, systolic BP $\geq 140 \mathrm{mmHg}$ or self-reported use of antihypertensive medication. ${ }^{19}$ Patients treated with $\alpha$-or $\beta$-adrenergic blocking agents, antiplatelet agents or with macroalbuminuria ( $\geq 500 \mathrm{mg} /$ day) or abnormal plasma creatinine concentrations $(\geq 1.2 \mathrm{mg} / \mathrm{dl})$ were also excluded from the study. Dyslipidemia was defined as fasting triglycerides $>200 \mathrm{mg} / \mathrm{dl}$, or high-density lipoprotein (HDL) cholesterol $\leq 45 \mathrm{mg} / \mathrm{dl}$ in females and $\leq 35 \mathrm{mg} / \mathrm{dl}$ in males. ${ }^{19}$ Hyperuricemia was defined as uric acid $>6.0 \mathrm{mg} / \mathrm{dl}$ in females or $>7.0 \mathrm{mg} / \mathrm{dl}$ in males. ${ }^{20}$ Chronic kidney disease (CKD) was defined as an estimated glomerular filtration rate (eGFR) $<60 \mathrm{ml} \cdot \mathrm{min}^{-1} \cdot 1.73 \mathrm{~m}^{-2} .^{21}$ Patients with an eGFR $<30 \mathrm{ml}$. $\mathrm{min}^{-1} \cdot 1.73 \mathrm{~m}^{-2}$ were excluded. This investigation was conducted according to the principles expressed in the Declaration of Helsinki. Prior informed consent in terms of gathering BRS measurements was obtained from all patients, and the study protocol was approved by the institutional review board of Oita University. Of the total 210 patients enrolled, we obtained accurate follow-up information for 3-10 years (mean 4.7 years) from 185 patients (94 males, 91 females; mean age 58土12 years, range $31-83$ years).

\section{BRS Measurement}

For the BRS assessment, all subjects were studied between 9:00 and 11:00 AM while supine in a quiet room. ${ }^{7}$ A catheter was inserted into the right cubital vein, and arterial BP was recorded noninvasively using tonometry (Jentow-7700; Nihon Colin, Komaki, Japan). ${ }^{7}$ Arterial BP and 12-lead ECG were monitored simultaneously. Data were stored in a PCM data recorder (RD-200T; TEAC, Tokyo, Japan). After an interval of $30 \mathrm{~min}$ to allow the patient's condition to stabilize, the patient was asked to breathe at a rate of 15 breaths/min using a metronome. BRS was assessed using the phenylephrine method. ${ }^{1}$ Phenylephrine $(2-3 \mu \mathrm{g} / \mathrm{kg})$ was injected over $15 \mathrm{~s}$ to increase systolic BP by $15-40 \mathrm{mmHg}$. BRS was calculated as the slope of the linear regression line relating the systolic $\mathrm{BP}$ changes to the RR interval changes. Regression lines with more than 20 data points and a correlation coefficient (r) $>0.8$ were accepted for analysis. The mean of the 2 slope values was taken as the BRS value. BRS was considered depressed if it was $<6 \mathrm{~ms} / \mathrm{mmHg}$. ${ }^{1,22}$

\section{Follow-up}

Most of the follow-up for patients occurred at Oita University Hospital. Information was also obtained for those patients whose follow-up was performed by a general practitioner or who were hospitalized in other departments. For the patients who died, the cause of death was documented with the help of the patients' family and general practitioner.

The endpoint was defined as the appearance of a major adverse cardiac and cerebrovascular event (MACCE), which 
Table 2. Number of Patients Achieving the Study Endpoints

\begin{tabular}{|c|c|c|c|c|}
\hline & \multicolumn{2}{|c|}{ Male } & \multicolumn{2}{|c|}{ Female } \\
\hline & $\begin{array}{c}\text { BRS } \geq 6.0 \\
(n=63)\end{array}$ & $\begin{array}{c}\text { BRS }<6.0 \\
(n=31)\end{array}$ & $\begin{array}{c}\text { BRS } \geq 6.0 \\
(n=36)\end{array}$ & $\begin{array}{c}\text { BRS }<6.0 \\
(n=55)\end{array}$ \\
\hline Cardiovascular death & 0 & 1 & 1 & 2 \\
\hline Nonfatal MI & 0 & 0 & 0 & 3 \\
\hline Coronary revascularization & 1 & 1 & 0 & 2 \\
\hline Stroke & 0 & 0 & 1 & 4 \\
\hline Congestive heart failure & 1 & 0 & 0 & 3 \\
\hline Total & 2 & 2 & 2 & 14 \\
\hline
\end{tabular}

MI, myocardial infarction. Other abbreviation see in Table 1.

\begin{tabular}{|c|c|c|}
\hline \multirow[b]{2}{*}{ Risk factor } & \multicolumn{2}{|c|}{ HR } \\
\hline & $\begin{array}{c}\text { Univariate } \\
(95 \% \mathrm{Cl})\end{array}$ & $\begin{array}{c}\text { Multivariate } \\
(95 \% \mathrm{Cl})\end{array}$ \\
\hline Age & $1.09(0.98-1.23)$ & NS \\
\hline $\mathrm{BMI} \geq 25$ & $2.18(0.78-9.83)$ & NS \\
\hline Hypertension & $0.90(0.31-2.59)$ & NS \\
\hline Dyslipidemia & $(-)$ & NS \\
\hline Hyperuricemia & $1.21(0.27-3.39)$ & NS \\
\hline Current smoker & $1.09(0.39-4.88)$ & NS \\
\hline $\mathrm{HbA}_{1 \mathrm{c}}(\%)$ & $1.48(0.83-2.55)$ & NS \\
\hline Chronic kidney disease & $0.66(0.23-1.91)$ & NS \\
\hline BRS $<6$ & $1.50(0.52-4.33)$ & NS \\
\hline
\end{tabular}

$\mathrm{HR}$, hazard ratio; $\mathrm{Cl}$, confidence interval. Other abbreviations see in Table 1.

included cardiovascular mortality, nonfatal MI, coronary revascularization through angioplasty or bypass, stroke and congestive heart failure requiring admission. Using this combined criterion, only the first event was taken into account in the statistical analysis.

\section{Statistical Analysis}

Data are presented as mean $\pm \mathrm{SD}$. The chi-square test was used for categorical variables, and the analysis of variance (ANOVA) test was used for continuous variables. Differences between 2 groups were analyzed by Student's t-test. One-way ANOVA followed by Tukey-Kramer honestly significant difference test was used to test differences among the preserved BRS males, the depressed BRS males, the preserved BRS females, and the depressed BRS females. Kaplan-Meier MACCE-free analysis was used to compare MACCE-free times among the 4 groups. To test for differences between the resulting curves, the log-rank test was used. Univariate and multivariate Cox proportional hazard regression analyses were performed to identify independent predictors (risk factors) of MACCE. Risk factors entered into the risk model included age, body mass index, smoking status, hemoglobin (Hb) Alc, hypertension, dyslipidemia, hyperuricemia, CKD and BRS. Results are given as hazard ratios (HR) with $95 \%$ confidence intervals $(\mathrm{CI})$. A value of $\mathrm{P}<0.05$ was considered significant. All computations were performed with JMP (JMP version 6.0.3; SAS, Cary, NC, USA), running under Windows 2003 XP (Microsoft, Redmond, WA, USA).

\begin{tabular}{|c|c|c|}
\hline \multirow[b]{2}{*}{ Risk factor } & \multicolumn{2}{|c|}{ HR } \\
\hline & $\begin{array}{c}\text { Univariate } \\
(95 \% \mathrm{Cl})\end{array}$ & $\begin{array}{c}\text { Multivariate } \\
(95 \% \mathrm{Cl})\end{array}$ \\
\hline Age & $1.02(0.97-1.06)$ & NS \\
\hline $\mathrm{BMI} \geq 25$ & $1.72(1.01-3.25)$ & NS \\
\hline Hypertension & $2.39(1.26-6.04)$ & NS \\
\hline Dyslipidemia & $2.71(1.22-11.6)$ & NS \\
\hline Hyperuricemia & $2.53(1.54-4.35)$ & $2.40(1.28-4.67)$ \\
\hline Current smoker & $1.08(0.52-1.92)$ & NS \\
\hline $\mathrm{HbA}_{1 \mathrm{c}}(\%)$ & $0.91(0.68-1.19)$ & NS \\
\hline Chronic kidney disease & $0.58(0.35-0.97)$ & NS \\
\hline BRS $<6$ & $2.11(1.11-5.32)$ & $3.17(1.44-8.88)$ \\
\hline
\end{tabular}

Abbreviations see in Tables 1,3.

\section{Results}

\section{Patients' Characteristics}

There were no significant differences in age or severity and duration of DM between the male and female patients. When compared to males, the BRS value in female patients was significantly lower $(9.21 \pm 6.0$ vs. $5.90 \pm 5.1 \mathrm{~ms} / \mathrm{mmHg}, \mathrm{P}<0.0001)$. Baseline characteristics of the 4 groups (preserved BRS males, depressed BRS males, preserved BRS females, depressed BRS females) are shown in Table 1. Comparing all male patients with all female patients, there were no differences in age $(58 \pm 11$ vs. $58 \pm 12$ years), duration of DM ( $10 \pm 9$ vs. $9 \pm 7$ years $)$ or systolic BP $(125 \pm 20$ vs. $129 \pm 20 \mathrm{mmHg})$. Regarding the differences among the 4 groups, the mean age was higher in the depressed BRS female patients than in the preserved BRS females $(\mathrm{P}<0.05)$. The duration of $\mathrm{DM}$ was longer in the depressed BRS females than in the preserved BRS females $(\mathrm{P}<0.05)$. Among the 4 groups, there was no difference in the percentage of patients treated with angiotensin II receptor blockers (ARBs), angiotensin converting enzyme inhibitors (ACEI), calcium channel blockers (CCB) or statins. Systolic $\mathrm{BP}$ was higher in the depressed BRS females than in the preserved BRS males and females $(\mathrm{P}<0.0005)$. However, HDL cholesterol was lower in the depressed BRS males than in the preserved BRS females and the depressed BRS females $(\mathrm{P}<$ $0.005)$. Uric acid was higher in the preserved and depressed BRS males than in the depressed BRS females $(\mathrm{P}<0.01)$. The eGFR was lower in the depressed BRS males than in the preserved BRS females $(\mathrm{P}<0.05)$. BRS was lower in the depressed males and females than in the preserved males and females $(\mathrm{P}<0.0001)$ 


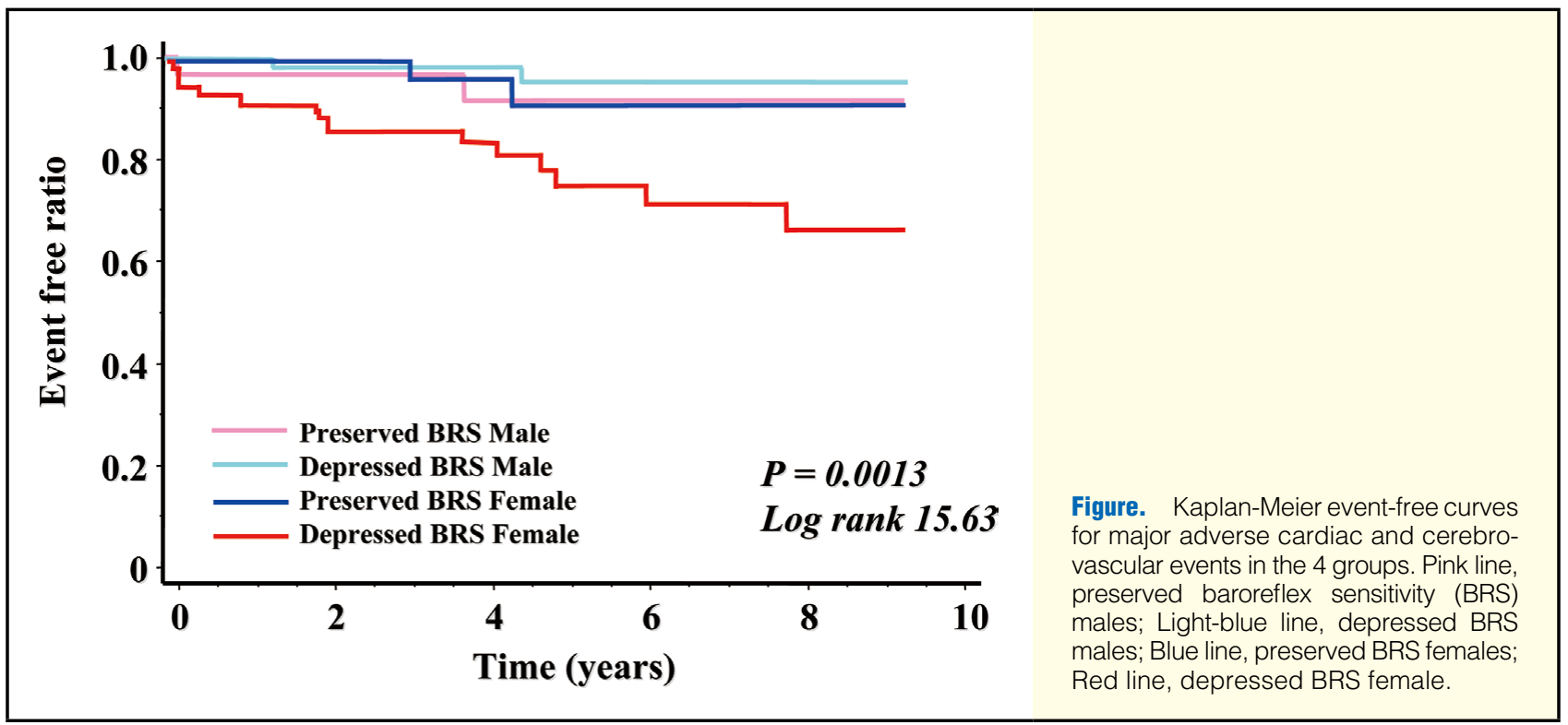

\section{Patients' Outcomes}

During follow-up, 8 patients died $(4.3 \%)$ : 4 were cardiovascular deaths and 4 were attributed to non-cardiovascular causes. All-cause mortality rates were not significantly different among the 4 groups. There were no significantly differences in the total cardiovascular mortalities of the 4 groups: $0 \%(0 / 63)$ in the preserved BRS males, $3.2 \%(1 / 31)$ in the depressed BRS males, $2.8 \%(1 / 36)$ in the preserved BRS females, and $3.6 \%(2 / 55)$ in the depressed BRS females.

\section{Univariate and Multivariate Predictors of MACCE}

During follow-up, 20 patients presented with a MACCE $(10.8 \%)$ and of these 20 MACCEs, 4 were cardiovascular deaths, 3 were nonfatal MI, 4 were coronary revascularizations, 5 were strokes, and 4 were congestive heart failure (Table 2). MACCEs occurred more frequently in the depressed BRS females $(25.5 \%)$ than in the preserved BRS males (3.2\%), the depressed BRS males $(6.5 \%)$ or the preserved BRS females $(5.6 \%)(\mathrm{P}<0.001)$. Results of univariate and multivariate Cox proportional hazards regression analysis of MACCE in males and females are presented in Tables 3,4 . In male patients, univariate analysis revealed no significant factors associated with MACCE (Table 3), whereas in female patients, body mass index $\geq 25$, the prevalence of hypertension, dyslipidemia, hyperuricemia, CKD and depressed BRS were associated with MACCE (Table 4). In the multivariate analysis using risk factors including age, body mass index $\geq 25$, hypertension, dyslipidemia, hyperuricemia, CKD, smoking status, hemoglobin $\mathrm{A}_{1 \mathrm{c}}$, and depressed BRS, both hyperuricemia (HR 2.61, 95\%CI 1.43-4.92, $\mathrm{P}=0.0019$ ) and depressed BRS (HR 3.26, 95\% CI $1.50-9.00, \mathrm{P}=0.0018$ ) independently predicted the incidence of MACCE (Table 4).

\section{Kaplan-Meier MACE-Free Estimation}

The MACCE-free ratio as evaluated by Kaplan-Meier analysis was significantly lower in the depressed BRS females than in the other groups (log-rank 15.63, $\mathrm{P}=0.0013$ ) (Figure).

\section{Discussion}

In the present study, 185 Japanese type 2 DM patients were followed for a mean period of 4.7 years, and MACCE occurred in 20 of them. The most important finding is that a depressed BRS value can accurately predict cardiovascular events, especially in female patients with type $2 \mathrm{DM}$. To the best of our knowledge, this report is the first to demonstrate a gender difference in the ability of the BRS value obtained using the phenylephrine method to predict long-term cardiac and cerebrovascular events in Japanese type 2 DM patients who do not have structural heart disease/severe complications. The MACCE-free ratio as evaluated by Kaplan-Meier analysis was significantly lower in the depressed BRS female group than in the other 3 groups.

Abdel-Rahman et al first reported in healthy young subjects that females had a smaller BRS value than males, ${ }^{12}$ and their finding that the baroreceptor reflex control of heart rate was significantly lower in females compared with the values obtained from males of similar age and basal BP suggested a weaker vagal response in females. Because the heart rate reduction in response to abrupt pressor stimuli mainly reflects the activity of the vagal component, their findings suggest that the cardiac vagal component plays a substantially smaller role in baroreflex-mediated bradycardia in females. Our result that the BRS value in female patients was significantly lower than in male patients is consistent with that finding. Laitinen et al reported $^{13}$ that females had lower BRS values and greater inter-individual variation than did males, but the slopes of the BRS-age regression lines in females and males did not differ. However, compared with males, there was a parallel downward shift of the BRS-age regression lines in females. It has been reported that $24 \%$ of middle-aged and older healthy females have a markedly depressed BRS $(<3 \mathrm{~ms} / \mathrm{mmHg})$, which has been associated with a high risk of arrhythmias in postinfarction patients. ${ }^{2,3}$ Huikuri et $\mathrm{al}^{23}$ suggested that the sex hormones could play a role in the gender-related difference in BRS. In their study, BRS was higher in postmenopausal women taking hormonal replacement therapy than in those who did not. Similarly, it has been previously reported that baroreflex-mediated control of heart rate is altered during the normal menstrual cycle. ${ }^{24}$ The baroreflex-mediated bradycardic response was augmented during the preovulatory phase and appeared to correlate with the plasma estradiol 
concentration, whereas baroreflex-mediated tachycardia was augmented during the early follicular phase. Significant correlations were observed between plasma estradiol concentrations and BRS assessed by the phenylephrine method and the Valsalva maneuver. ${ }^{24}$ Sevre et al demonstrated a significantly lower BRS in hypertensive subjects than in normotensive controls. ${ }^{15}$ Moreover, the reduction in BRS was most pronounced in the female group and did not reach statistical significance in men. BRS was also reduced in hypertensive women compared with hypertensive men. Previous studies have proposed that female sex hormones modeled the arterial layers, which are crucial to the arterial BP buffer capacity and hence BP variability and BRS. ${ }^{25-27}$ These findings imply that hypertensive women are more susceptible to cardiac events and arrhythmias than hypertensive men. ${ }^{15}$

During the past several decades, knowledge regarding gender differences in coronary heart disease has been emerging. Annual ischemic heart disease (IHD) population statistics continue to report a greater number of deaths for females than males. ${ }^{28}$ Diabetic females have significantly greater rates of IHD mortality than diabetic males, ${ }^{29,30}$ and a 3.3 -fold IHD risk compared with nondiabetic females. ${ }^{31}$ The 30 -year trends reveal marked cardiovascular disease mortality reduction for diabetic males but not for diabetic females. ${ }^{32}$ Our findings are compatible with previous results from INTERHEART, a large case-control study of more than 15,000 cases of acute MI, which concluded that DM was a more significant coronary risk among females than it was among males. ${ }^{33}$ Huxley et al explained why DM has a greater adverse affect in females than in males. According to their analysis, DM induces a more unfavorable cardiovascular risk profile among females. They found that women with DM not only have significantly higher levels of BP and lipids than males with DM but that the difference in the levels among people with and without DM was significant greater in females than it was in males. ${ }^{34}$ In our analysis, total cholesterol, low-density lipoprotein cholesterol, and $\mathrm{HbA}_{1 \mathrm{c}}$ were significantly higher in females than in males, but BP was no different between genders. Alternatively, the greater coronary risk associated with DM seen in females may reflect a treatment bias that favors males. A recent study found that males with DM or established cardiovascular disease are more likely to received aspirin, statins, or antihypertensive drugs than are females. ${ }^{35}$ Leslee et al hypothesized that females experienced more adverse outcomes compared with males because atherosclerotic IHD remains the current problem for therapeutic strategies. ${ }^{28}$ Recent data from the Euro Heart Survey of Stable Angina reported that females with IHD were less likely to receive coronary revascularization. One reason proposed for the lower rates of revascularization in females include the relatively poorer outcome and higher rates of complications in females undergoing either coronary bypass graft surgery or percutaneous revascularization. ${ }^{36}$ When compared to the preserved BRS female group, the depressed BRS females had a significantly longer duration of DM, higher BP, and were older. These factors may influence our observation that MACCE developed more frequently in the depressed BRS females than in the preserved BRS females. However, looking at the differences between depressed BRS males and depressed BRS females, there was no significant difference with respect to age, BP or duration of DM. The eGFR was lower in the depressed BRS males than in the preserved BRS females in this study. CKD patients defined as having reduced GFR have an increased risk of cardiovascular disease, ${ }^{37}$ and it has been also reported that CKD was associated with MACCE in young Japanese coronary artery disease patients. ${ }^{38}$ Although our analysis did not extract the presence of CKD as a risk for MACCE, the effects of renal function, as provided by eGFR, on cardiovascular autonomic function and prognosis should be further evaluated.

\section{Study Limitations}

First, because we enrolled patients without severe complications, the incidence of MACCE was small, which might make it difficult to analyze the data. Conversely, most of the patients with preserved BRS were free from MACE. Thus, compared to the positive predictive value of depressed BRS (17.6\%), the negative predictive value of preserved BRS $(96.0 \%)$ may be more clinically relevant. Second, clinical manifestations of diabetic autonomic neuropathy involve many systems, including cardiovascular, gastrointestinal, genitourinary, metabolic, sudomotor, and papillary. Because we did not quantitatively evaluate other autonomic neuropathies, their association with BRS remains unclear. Third, as shown in Table 1, there were significant differences, with respect to age, DM duration, systolic BP, HDL cholesterol, uric acid, and eGFR, among the 4 groups. All these factors might influence the BRS value. In fact, it has been established that increased arterial BP impairs BRS. ${ }^{39}$ Finally, we discussed cardiovascular autonomic neuropathy from the viewpoints of BRS, the arm of parasympathetic activity. Sympathetic abnormalities may be also involved, which should be evaluated in future studies using cardiac ${ }^{123}$ I-metaiodobenzylguanidine myocardial scintigraphy. ${ }^{7-11}$ Fourth, we could not evaluate the effects of the extent of changes in the patients' diabetic condition (ie, levels of plasma glucose and $\mathrm{HbA}_{1 c}$ ) on BRS and MACCE. Fifth, cardiovascular drugs, particularly ARB, ACEI, CCB and statin may be beneficial in improving BRS, which needs to be further investigated. Finally, the cut-off value of the BRS should be defined differently for each gender. We set it at $6 \mathrm{~ms} / \mathrm{mmHg}$. However, in fact, the cut-off line from analysis of the receiveroperator characteristics curve was $5.84 \mathrm{~ms} / \mathrm{mmHg}$ in females and $2.51 \mathrm{~ms} / \mathrm{mmHg}$ in males.

\section{Conclusion}

Our findings demonstrated that depressed BRS value can accurately predict cardiac cerebrovascular events, especially in female patients with type $2 \mathrm{DM}$. Once diabetic, a female who develops an impaired BRS has a worse prognosis than similar male. Intensive management and/or therapy may be needed in this population.

\section{Disclosure}

There is no financial support for the present study.

\section{References}

1. La Rovere MT, Bigger JT Jr, Marcus FI, Mortara A, Schwartz PJ. Baroreflex sensitivity and heart-rate variability in prediction of total cardiac mortality after myocardial infarction: ATRAMI (Autonomic Tone and Reflexes After Myocardial Infarction) Investigators. Lancet 1998; 351: 478-484.

2. La Rovere MT, Specchia G, Mortara A, Schwartz PJ. Baroreflex sensitivity, clinical correlates, and cardiovascular mortality among patients with a first myocardial infarction: A prospective study. Circulation 1988; 78: 816-824.

3. Farrell TG, Odemuyiwa O, Bashir Y, Cripps TR, Malik M, Ward $\mathrm{DE}$, et al. Prognostic value of baroreflex sensitivity testing after acute myocardial infarction. Br Heart J 1992; 67: 129-137.

4. Hohnloser SH, Klingenheben T, van de Loo A, Hablawetz E, Just $\mathrm{H}$, Schwartz PJ. Reflex versus tonic vagal activity as a prognostic parameter in patients with sustained ventricular tachycardia or ven- 
tricular fibrillation. Circulation 1994; 89: 1068-1073.

5. De Ferrari GM, Landolina M, Mantica M, Manfredini R, Schwartz PJ, Lotto A. Baroreflex sensitivity, but not heart rate variability, is reduced in patients with life-threatening ventricular arrhythmias long after myocardial infarction. Am Heart J 1995; 130: 473-480.

6. Robinson TG, Dawson SL, Eames PJ, Panerai RB, Potter JF. Cardiac baroreceptor sensitivity predicts long-term outcome after acute ischemic stroke. Stroke 2003; 34: 705-712.

7. Takahashi N, Nakagawa M, Saikawa T, Ooie T, Yufu K, Shigematsu $\mathrm{S}$, et al. Effect of essential hypertension on cardiac autonomic function in type 2 diabetic patients. J Am Coll Cardiol 2001; 38: 232-237.

8. Takahashi N, Anan F, Nakagawa M, Yufu K, Ooie T, Nawata T, et al. Microalbuminuria, cardiovascular autonomic dysfunction, and insulin resistance in patients with type 2 diabetes mellitus. Metabolism 2004; 53: 1359-1364.

9. Anan F, Takahashi N, Nakagawa M, Ooie T, Saikawa T, Yoshimatsu $\mathrm{H}$. High-sensitivity C-reactive protein is associated with insulin resistance and cardiovascular autonomic dysfunction in type 2 diabetic patients. Metabolism 2005; 54: 552-558.

10. Yufu K, Takahashi N, Nakagawa M, Hara M, Saikawa T, Yoshimatsu $\mathrm{H}$. Brain natriuretic peptide and cardiac autonomic function in type 2 diabetic patients. Diabetes Res Clin Pract 2006; 72: $12-19$.

11. Takahashi N, Anan F, Nakagawa M, Yufu K, Shinohara T, Tsubone $\mathrm{T}$, et al. Hypoadiponectinemia in type 2 diabetes mellitus in men is associated with sympathetic overactivity as evaluated by cardiac 123I-metaiodobenzylguanidine scintigraphy. Metabolism 2007; 56: 919-924.

12. Abdel-Rahman AR, Merrill RH, Wooles WR. Gender-related differences in the baroreceptor reflex control of heart rate in normotensive humans. J Appl Physiol 1994; 77: 606-613.

13. Laitinen T, Hartikainen J, Vanninen E, Niskanen L, Geelen G, Länsimies E. Age and gender dependency of baroreflex sensitivity in healthy subjects. J Appl Physiol 1998; 84: 576-583.

14. Hinojosa-Laborde C, Chapa I, Lange D, Haywood JR. Gender differences in sympathetic nervous system regulation. Clin Exp Pharmacol Physiol 1999; 26: $122-126$.

15. Sevre K, Lefrandt JD, Nordby G, Os I, Mulder M, Gans RO, et al. Autonomic function in hypertensive and normotensive subjects: The importance of gender. Hypertension 2001; 37: 1351-1356.

16. Tanaka M, Kimura T, Goyagi T, Nishikawa T. Gender differences in baroreflex response and heart rate variability in anaesthetized humans. Br J Anaesth 2004; 92: 831 - 835 .

17. Barantke M, Krauss T, Ortak J, Lieb W, Reppel M, Burgdorf C, et al. Effects of gender and aging on differential autonomic responses to orthostatic maneuvers. J Cardiovasc Electrophysiol 2008; 19: $1296-1303$.

18. Kuzuya T, Nakagawa S, Satoh J, Kanazawa Y, Iwamoto Y, Kobayashi M, et al. Report of the committee on the classification and diagnostic criteria of diabetes mellitus. Diabetes Res Clin Pract 2002; 55: $65-85$

19. Liao D, Sloan RP, Cascio WE, Folsom AR, Liese AD, Evans GW, et al. Multiple metabolic syndrome is associated with lower heart rate variability: The Atherosclerosis Risk in Communities Study. Diabetes Care 1998; 21: 2116-2122.

20. Hakoda M, Masunari N, Yamada M, Fujiwara S, Suzuki G, Kodama K, et al. Serum uric acid concentration as a risk factor for cardiovascular mortality. J Rheumatol 2005; 32: 906-912.

21. National Kidney Foundation. K/DOQI clinical practice guidelines for chronic kidney disease: Evaluation, classification, and stratification. Am J Kidney Dis 2002; 39(Suppl 1): S1-S266.

22. Okada N, Takahashi N, Yufu K, Murozono Y, Wakisaka O, Shinohara $\mathrm{T}$, et al. Baroreflex sensitivity predicts cardiovascular events in patients with type 2 diabetes mellitus without structural heart disease. Circ J 2010; 74: 1379-1383.

23. Huikuri HV, Pikkujämsä SM, Airaksinen KE, Ikäheimo MJ, Rantala $\mathrm{AO}$, Kauma H, et al. Sex-related differences in autonomic modulation of heart rate in middle-aged subjects. Circulation 1996; 94: $122-125$.

24. Tanaka M, Sato M, Umehara S, Nishikawa T. Influence of menstrual cycle on baroreflex control of heart rate: Comparison with male volunteers. Am J Physiol Regul Integr Comp Physiol 2003; 285: R1091-R1097.

25. Heijden-Spek JJ, Staessen JA, Fagard RH, Hoeks AP, Boudier HA, van Bortel LM. Effect of age on brachial artery wall properties differs from the aorta and is gender dependent: A population study. Hypertension 2000; 35: 637-642.

26. Sator MO, Joura EA, Gruber DM, Obruca A, Zeisler H, Egarter C, et al. Non-invasive detection of alterations of the carotid artery in pregnant women with high-frequency ultrasound. Ultrasound Obstet Gynecol 1999; 13: 260-262.

27. Koh KK, Cardillo C, Bui MN, Hathaway L, Csako G, Waclawiw MA, et al. Vascular effects of estrogen and cholesterol-lowering therapies in hypercholesterolemic postmenopausal women. Circulation 1999; 99: 354-360.

28. Shaw LJ, Bugiardini R, Merz CN. Women and ischemic heart disease: Evolving knowledge. J Am Coll Cardiol 2009; 54: 1561-1575.

29. Kanaya AM, Grady D, Barrett-Connor E. Explaining the sex difference in coronary heart disease mortality among patients with type 2 diabetes mellitus: A meta-analysis. Arch Intern Med 2002; 162: $1737-1745$.

30. Barrett-Connor EL, Cohn BA, Wingard DL, Edelstein SL. Why is diabetes mellitus a stronger risk factor for fatal ischemic heart disease in women than in men? The Rancho Bernardo Study. JAMA 1991; 265: 627-631.

31. Spencer EA, Pirie KL, Stevens RJ, Beral V, Brown A, Liu B, et al; Million Women Study Collaborators. Diabetes and modifiable risk factors for cardiovascular disease: The prospective Million Women Study. Eur J Epidemiol 2008; 23: 793 -799.

32. Gregg EW, Gu Q, Cheng YJ, Narayan KM, Cowie CC. Mortality trends in men and women with diabetes, 1971 to 2000. Ann Intern Med 2007; 147: 149-155.

33. Yusuf S, Hawken S, Ounpuu S, Dans T, Avezum A, Lanas F, et al; INTERHEART Study Investigators. Effect of potentially modifiable risk factors associated with myocardial infarction in 52 countries (the INTERHEART study): Case-control study. Lancet 2004; 364: 937-952.

34. Huxley R, Barzi F, Woodward M. Excess risk of fatal coronary heart disease associated with diabetes in men and women: Metaanalysis of 37 prospective cohort studies. BMJ 2006; 332: 73-78.

35. Wexler DJ, Grant RW, Meigs JB, Nathan DM, Cagliero E. Sex disparities in treatment of cardiac risk factors in patients with type 2 diabetes. Diabetes Care 2005; 28: 514-520.

36. Daly C, Clemens F, Lopez Sendon JL, Tavazzi L, Boersma E, Danchin N, et al; Euro Heart Survey Investigators. Gender differences in the management and clinical outcome of stable angina. Circulation 2006; 113: 490-498.

37. Sakuma M, Nakamura M, Tanaka F, Onoda T, Itai K, Tanno K, et al. Plasma B-type natriuretic peptide level and cardiovascular events in chronic kidney disease in a community-based population. Circ J 2010; 74: 792-797.

38. Furukawa Y, Ehara N, Taniguchi R, Haruna Y, Ozasa N, Saito N, et al; CREDO-Kyoto Investigators. Coronary risk factor profile and prognostic factors for young Japanese patients undergoing coronary revascularization. Circ J 2009; 73: 1459-1465.

39. Skrapari I, Tentolouris N, Katsilambros N. Baroreflex function: Determinants in healthy subjects and disturbances in diabetes, obesity and metabolic syndrome. Curr Diabetes Rev 2006; 3: 329-338. 